\title{
Mirtazapine Augmentation for Selective Serotonin Reuptake Inhibitor-Induced Sexual Dysfunction: A Retropective Investigation
}

\author{
Murad Atmaca ${ }^{\bowtie}$, Sevda Korkmaz, Mehtap Topuz, and Osman Mermi \\ Department of Psychiatry, School of Medicine, Firat University, Elazig, Turkey
}

The aim of the present study was to retrospectively identify sexual dysfunction changes in the patients under mirtazapine-augmented serotonin reuptake inhibito (SSRI) treatment. The study comprised medical records of 20 outpatients, under mirtazapine-augmented SSRI treatment for their major depressive disorder, who had been selected among the patients that had developed sexual dysfunction to previous treatment as monotherapy, with SSRI for at least six weeks. These drugs were maintained and mirtazapine were added (15-45 $\mathrm{mg} /$ day). There was a significant difference in scores between baseline and week 4 or week 8 on the both Hamilton Depression Rating and Arizona Sexual Experience Scale. According to Clinical Global Impression-Improvement, $68.4 \%$ of the patients were responders. The use of low-dose mirtazapine as an add-on treatment to SSRIs appears to be an effective and well-tolerated augmenttaion for sexual dysfunction caused by SSRIs.

Psychiatry Investig 2011;8:55-57

Key Words Mirtazapine, Sexual dysfunction, SSRI.

\section{INTRODUCTION}

Sexual side effects are a common and bothersome reaction to most available antidepressants, frequently leading to cessation of treatment, with a rate of $10-30 \%$ for serotonin reuptake inhibitors (SSRIs). ${ }^{1}$ One of the approaches for antidepressantinduced sexual dysfunction is augmentation of another agent to ongoing treatment. Mirtazapine has a unique tolerability profile, since the specific postsynaptic $5-\mathrm{HT}_{2}$ and $5-\mathrm{HT}_{3}$ receptor blockade of mirtazapine provides early antidepressant effects without causing unwanted serotonin-related side effects, particularly sexual dysfunction; ${ }^{2}$ in contrast, these features may relieve sexual function disorders.

Therefore, the aim of this study was to identify sexual dysfunction in patients with major depressive disorder under the mirtazapine-augmented SSRI treatment.

Received: April 26, 2010 Revised: October 11, 2010

Accepted: October 20, 2010 Available online: November 20, 2010

$\triangle$ Correspondence: Murad Atmaca, MD

Department of Psychiatry, School of Medicine, Firat (Euphrates) Universitesi, Firat Tip Merkezi, Psikiyatri Anabilim Dali 23119, Elazig, Turkey

Tel: +90-424-233-3555/1578, Fax: +90-424-238-7688,

E-mail: matmaca_p@yahoo.com

(a) This is an Open Access article distributed under the terms of the Creative Commons Attribution Non-Commercial License (http://creativecommons.org/licenses/by$\mathrm{nc} / 3.0$ ) which permits unrestricted non-commercial use, distribution, and reproduction in any medium, provided the original work is properly cited.

\section{METHODS}

This is a retrospective observational study in which the medical records of 20 heterosexual outpatients (11 males and 9 females), under the mirtazapine augmented SSRI treatment for their major depressive disorder who had been selected among the patients that had developed sexual dysfunction to previous treatment, in monotherapy, with SSRI for least for six weeks. The mean age was $27.7 \pm 5.8$ years (range $=20-46$ years). Twelve of the patients graduated from high school and university, five from elementary school and three from primary school. In regard to socioeconomical status, ten had low income level, whereas six had moderate and four had high. The procedures followed were in accordance with the Helsinki Declaration of 1975 , as revised in 1983, with written informed consents and ethics approval.

To exclude the organic sexual dysfunctions, biochemical evaluations were performed. Exclusion criteria were the followings; being over 45 years old, a concurrent medical illness affecting sexual function, the existence of polypharmacy with another psychotropic drug (except for benzodiazepines), previous or current alcohol and substance abuse or dependence, the presence of any endocrinological state, treatment with any hormones, and a history of pre-existing sexual dysfunction.

Antidepressant drugs that the patients had received were es- 
citalopram ( $\mathrm{n}=5,40-60 \mathrm{mg} /$ day), sertraline $(\mathrm{n}=4,100-200 \mathrm{mg} /$ day), clomipramine ( $n=3,20-60 \mathrm{mg} /$ day), fluvoxamine $(\mathrm{n}=3$, $100-300 \mathrm{mg} /$ day), paroxetine $(\mathrm{n}=3,20-60 \mathrm{mg} /$ day $)$ and citalopram ( $\mathrm{n}=2,20-60 \mathrm{mg} /$ day). These antidepressants were maintained and mirtazapine (15-45 mg/day) was added. No concomitant psychotropic medication except for benzodiazepines was permitted.

They were screened by using Hamilton Depression Rating (HAM-D) $)^{3}$, Clinical Global Impression-Improvement (CGI-I) and Arizona Sexual Experience Scale (ASEX) ${ }^{4}$ scales at week 4, and 8 .

Data were statistically analyzed using SPSS Microsoft Windows 9.05. Paired t-test was used. Results are given in the text as means \pm SD, with a $p$ value of $<0.05$.

\section{RESULTS}

Prior to adding mirtazapine, the most frequently experienced sexual dysfunctions associated SSRIs were decreased libido (55\%; four patients receiving paroxetine, three patients receiving clomipramine, two patients receiving fluvoxamine, and two patients taking sertraline), followed by erectile dysfunction (36.4\% of the males; two patients receiving paroxetine, one patient receiving clomipramine, and one patient receiving sertraline), delay of orgasm or ejaculation ( $25 \%$; two patients receiving clomipramine, two patients receiving paroxetine, and one patient receiving citalopram), anorgasmia or no ejaculation (10\%; one patient receiving paroxetine, and one patient receiving citalopram), and lubrication disorder in one patient receiving clomipramine (11.1\% of the females).

Of the 20 patients participating in the augmentation, only one did not complete the study because of oversedation and increased appetite. The mean HAM-D score was $16.8 \pm 4.4$ at baseline, $11.2 \pm 2.4$ at week 4 , and $9.4 \pm 2.2$ at week 8. Paired t-tests revealed a significant difference on HAM-D scores between baseline and week $4(\mathrm{p}<0.05)$ or week $8(\mathrm{p}<0.01)$. The mean ASEX score was $23.3 \pm 4.2$ at baseline, $17.0 \pm 3.3$ at week 4 , and $11.8 \pm$ 2.6 at week 8 . There was a significant difference between baseline and week $4(\mathrm{p}<0.05)$ or week $8(\mathrm{p}<0.01)$ in scores on the ASEX (Table 1). Responders and nonresponders did not differ in sex, age and HAM-D scores at baseline ( $\mathrm{p}>0.05)$.

Table 1. HAM-D, ASEX and CGI-I scale scores during treatment*

\begin{tabular}{llll}
\hline Weeks & HAM-D & \multicolumn{1}{c}{ ASEX } & CGI-I \\
\hline 0 & $16.8 \pm 4.4$ & $23.3 \pm 4.2$ & - \\
4 & $11.2 \pm 2.6^{* *}$ & $17.0 \pm 3.3^{* *}$ & $3.3 \pm 1.1$ \\
8 & $9.4 \pm 2.2^{* * *}$ & $11.8 \pm 2.4^{* * *}$ & $2.0 \pm 1.2^{* * *}$ \\
\hline
\end{tabular}

*used paired t-test, ${ }^{* *} \mathrm{p}<0.05,{ }^{* * *} \mathrm{p}<0.01$ (statistical significance of change according to baseline). HAM-D: Hamilton Depression Rating, ASEX: Arizona Sexual Experience Scale, CGI-I: Clinical Global Impression-Improvement
There was no correlation between decrease in HAM-D scores and that in ASEX scores $(r=0.07, p>0.05)$. At the end of the study, seven patients $(36.8 \%)$ were rated as very much improved (CGI$\mathrm{I}=1)$, and six patients (31.6\%) were rated as much improved (CGI-I=2). Thus, $68.4 \%$ of the patients were responders. At the end point, the majority of the patients were taking low doses of mirtazapine ( $15 \mathrm{mg}$ per day in ten patients, $30 \mathrm{mg}$ per day in five patients and $45 \mathrm{mg}$ per day in four patients).

The combination of SSRI-mirtazapine was generally well-tolerated. Ten patients complained of side effects. The most common side effects were sedation (6 patients), weight gain up to 3 $\mathrm{kg}$ (2 patients).

\section{DISCUSSION}

This retrospective study showed that in patients reporting sexual dysfunction associated with SSRIs, the addition of mirtazapine provided considerable improvement in sexual function.

A variety of strategies have been reported in the management of SSRI-induced sexual dysfunction, including dose reduction, drug holidays, substitution of another antidepressant drug, and various augmentation strategies, including use of sildenafil citrate, buspirone, and others. ${ }^{5,6}$

There are limited studies regarding mirtazapine use in patients with antidepressant-induced sexual dysfunction. Koutouvidis et al. ${ }^{7}$ and Gelenberg et al. ${ }^{8}$ reported the patients who had experienced sexual dysfunction while taking an SSRI were switched to mirtazapine and found that majority of the patients returned to normal sexual functioning. A mirtazapine augmentation study of patients with SSRI-induced sexual dysfunction which also had comparison groups of olanzapine, yohimbine, and placebo addition, showed that there was statistically significant improvement on most measures for the overall group of patients. ${ }^{9}$ But that study included only pre-menopausal patients with orgasmic dysfunction. Recently, Ozmenler et al. ${ }^{10}$ evaluated the effect of mirtazapine augmentation in patients with sexual dysfunction induced by current SSRI treatment and concluded that mirtazapine augmentation might be a good choice for the treatment of SSRI-induced sexual dysfunction. To our knowledge, however, the data reported in the present study when excluded for Ozmenler et al's study represents the first assessment of the efficacy of mirtazapine augmentation in both male and female patients with a variety of sexual dysfunctions. Mirtazapine, an $\alpha_{2}$ antagonist, is also a unique antidepressant that enhances noradrenergic and $5-\mathrm{HT}_{1 \mathrm{~A}}$-activated neurotransmission; it does not inhibit norepinephrine or serotonin reuptake. In addition, mirtazapine causes blockade of postsynaptic $5-\mathrm{HT}_{2}$ and $5-\mathrm{HT}_{3}$ receptors, which should spare sexual function. We suggest that the postsynaptic 5-HT antagonistic effects of mirtazapine, combined with its presynaptic $\alpha_{2}$-adrenoreceptor blo- 
ckage are the mechanism of action that reverses the sexual dysfunction induced by SSRIs. On the other hand, since adverse sexual effects related to SSRI treatment are believed to be mediated through 5- $\mathrm{HT}_{2}$ stimulation, possible relief of symptoms may result from blocking these receptors by mirtazapine. ${ }^{11}$

It is likely that mirtazapine activates noradrenaline neuronal activity and correlates noradrenaline and dopamine by inhibiting $\mathrm{a}_{2}$-adrenoceptor in the medial prefrontal cortex and occipital cortex. Dopamine, released in several major integrative areas before and/or during copulation, facilitates sexual motivation, motor performance, and genital reflexes. ${ }^{12}$ These different properties of mirtazapine may account for its usefulness in antidepressant-induced sexual dysfunctions caused by other antidepressants.

The findings should be subject to some limitations. Firstly, the retrospective design and sample size were major limitations. Furthermore, no control group was used. In fact, in the present study, no correlation was found between decrease in HAM-D scores and that in ASEX scores. Therefore, it appears the improvements in sexual functions to be independent from decrease in depressive state.

In conclusion, the results of our study reported herein demonstrate that mirtazapine may be beneficial in patients with SSRI-induced sexual dysfunction.

\section{REFERENCES}

1. Hu XH, Bull SA, Hunkeler EM, Ming E, Lee JY, Fireman B, et al. Incidence and duration of side effects and those rated as bothersome with selective serotonin reuptake inhibitor treatment for depression: patient report versus physician estimate. J Clin Psychiatry 2004;65:959-965.

2. Devoto P, Flore G, Pira L, Longu G, Gessa GL Mirtazapine-induced corelease of dopamine and noradrenaline from noradrenergic neurons in the medial prefrontal and occipital cortex. Eur J Pharmacol 2004;487: 105-111.

3. Hamilton M. A rating scale for depression. J Neurol Neurosurg Psychiatry 1960;23:56-62.

4. McGahuey CA, Gelenberg AJ, Laukes CA, Manber R, McKnight KM, Moreno FA, et al. The Arizona Sexual Experience Scale: validity and reliability. Proceedings of the Annual Meeting of the American Psychiatric Association 1997:17-22.

5. Aizenberg D, Naor S, Zemishlany Z, Weizman A. The serotonin antagonist mianserin for treatment of serotonin reuptake inhibitor-induced sexual dysfunction in women: an open-label add-on study. Clin Neuropharmacol 1999;22:347-350.

6. Hollander E, McCarley A. Yohimbine treatment of sexual side effects induced by serotonin reuptake blockers. J Clin Psychiatry 1992;53:207209.

7. Koutouvidis N, Pratikakis M, Fotiadou A. The use of mirtazapine in a group of 11 patients following poor compliance to selective serotonin reuptake inhibitor treatment due to sexual dysfunction. Int Clin Psychopharmacol 1999;14:253-255.

8. Gelenberg AJ, McGahuey C, Laukes C, Okayli G, Moreno F, Zentner L, et al. Mirtazapine substituon in SSRI-induced sexual dysfunction. J Clin Psychiatry 2000;61:356-360.

9. Michelson D, Kociban K, Tamura R, Morrison MF. Mirtazapine, yohimbine or olanzapine augmentation therapy for serotonin reuptake-associated female sexual dysfunction: a randomized, placebo controlled trial. J Psychiatr Res 2002;36:147-152.

10. Ozmenler NK, Karlidere T, Bozkurt A, Yetkin S, Doruk A, Sutcigil L, et al. Mirtazapine augmentation in depressed patients with sexual dysfunction due to selective serotonin reuptake inhibitors. Hum Psychopharmacol 2008;23:321-326.

11. Montgomery SA. Safety of mirtazapine: a review. Int Clin Psychopharmacol 1995;10 Suppl 4:37-45.

12. Hull EM, Muschamp JW, Sato S. Dopamine and serotonin: influences on male sexual behavior. Physiol Behav 2004;83:291-307. 